\title{
Uncommon testicular metastasis of a primary neuroendocrine tumour of the lung
}

\author{
Ingrid L. Birker, MD; ${ }^{*}$ Johan A. van der Zee, MD; ${ }^{\dagger}$ Karin M. Keizer, $M D^{\varsigma}$
}

*St. Lucas Andreas Hospital, Amsterdam, The Netherlands; † Department of Urology, St. Lucas Andreas Hospital, Amsterdam, The Netherlands; §Department of Pathology, Onze Lieve Vrouwe Gasthuis, Amsterdam, The Netherlands

Cite as: Can Urol Assoc J 2013;7(9-10):e614-7. http://dx.doi.org/10.5489/cuaj.398 Published online September 10, 2013.

\section{Abstract}

A 52-year-old male presented with an asymptomatic palpable mass of the right testicle. Ultrasound confirmed the presence of a testicular tumour and a hemicastration was performed. None of the testis cancer-related tumour markers were elevated and histological findings revealed a neuroendocrine carcinoma, possibly a metastasis from another primary site. The radiological findings showed a lesion in the lung, and a positron emission tomography (PET)-scan was made. The PET scan revealed an increased fluorodeoxyglucose (FDG) uptake in the pulmonary lesion. It also showed lymphatic and hepatic metastases. The patient had no complaints besides a palpable testicular mass and was diagnosed with a cT1aN3M1b neuroendocrine carcinoma of the lower left field of the lung, stage IV. To our knowledge, the presentation of testicular metastasis of a neuroendocrine carcinoma of the lung has not been described in the literature. No curative options were available and the patient is being treated with salvage chemotherapy.

\section{Introduction}

Primary testicular cancer is the most common solid malignancy in men between the ages of 20 and 45; it is rare in patients under 15 and over 60 . It constitutes $1 \%$ to $2 \%$ of all male cancers and 5\% of all urological tumours, and is considered the most curable cancer. Most are germ cell tumours. ${ }^{1}$ Neuroendocrine (carcinoid) tumours (NETs) of the testes represent less than $1 \%$ of all testicular tumours. ${ }^{2}$

\section{Case report}

A 52-year-old vital, slender male presented to the outpatient clinic with a palpable mass in the right testicle, which he had noticed a couple of weeks before. His medical history included one session of prostate biopsies in 2009 because of an elevated PSA (prostate-specific antigen) level, all of which were benign. Other than the tender mass, he had no further complaints. Ultrasound showed a suspect, hypo-echogene, vascularized lesion, $2 \mathrm{~cm}$, in the right testicle. The other testicle showed no pathology.

A hemicastration was performed on the right side. Three tumour markers were measured preoperatively and none were elevated: lactate dehydrogenase $(\mathrm{LDH}) 247 \mathrm{U} / \mathrm{L}$ (normal $<250 \mathrm{U} / \mathrm{L}$ ), human chorionic gonadotropin (hCG) $<2.0 \mathrm{U} / \mathrm{L}$ (normal range: 0-5 U/L) and alpha fetoprotein (aFP) $2.9 \mathrm{ug} / \mathrm{L}$ (normal $<10 \mathrm{ug} / \mathrm{L}$ ). A computed tomography (CT) scan of the thorax and abdomen was made to exclude metastases. It showed an unusual, possibly metastatic lesion in the lower field of the left lung; it was partially solid, partially cystic. Furthermore, it revealed multiple lesions in the liver, also suspect for metastases (Fig. 1).

The pathologist showed the unusual histopathological findings during a multidisciplinary meeting. Immunohistochemical markers for malignant germ cell tumours (e.g., placental alkaline phosphatase [PLAP] and CD30) were negative, which ruled out (non)-seminoma and embryonal carcinoma. Four neuroendocrine markers (synaptophysin, chromogranin, CD56 and keratin) were all positive, suggesting it to be a NET (Fig. 2a, Fig. 2b, Fig. 2c, Fig. $2 \mathrm{~d}$ ). The thyroid transcription factor 1 (TTF-1) was positive (Fig. 3). This is nearly $100 \%$ specific, though not so sensitive, for the lung primary in NETs. ${ }^{3}$ The final histopathological conclusion was a neuroendocrine carcinoma, grade 3, thyroid transcription factor 1 (TTF-1) positive, without necrosis.

The somatostatin receptor scintigraphy (SRS) to search for a primary in the gastro-intestinal tract was negative. A PET/ 


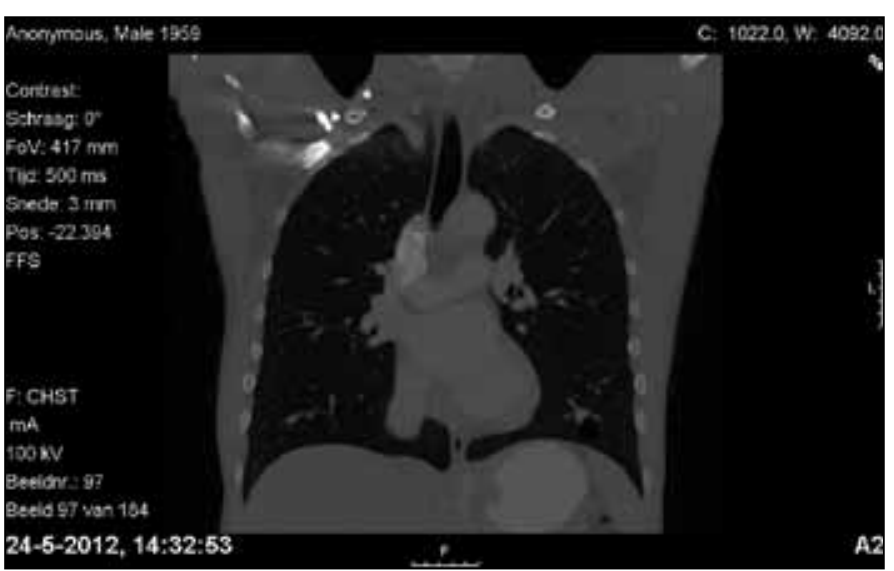

Fig. 1. A computed tomography scan showing possible metastases.

CT scan showed an increased fluorodeoxyglucose (FDG) uptake in the suspect lesion in the lower field of the left lung (Fig. 4a, Fig. 4b). It also revealed pathological mediastinal and hilar lymph nodes and extended uptake in the liver.

This case report describes a healthy, vital 52-year old-man with no complaints of dyspnoe, fatigue or loss of weight with a cT1aN3M1b neuroendocrine carcinoma of the lung, stage IV which presented itself as a palpable testicular tumour. The poor prognosis, the fact that there are no curative options, was discussed with the patient. The patient has now started salvage chemotherapy.

\section{Discussion}

NETs of the testes represent less than $1 \%$ of all testicular tumours. ${ }^{2}$ They originate from neuroendocrine cells, and can be divided into different embryological sites of origin: tumours of the fore-gut, the mid-gut and hind-gut. The sites most often affected are the gastrointestinal tract (65\%) fol-

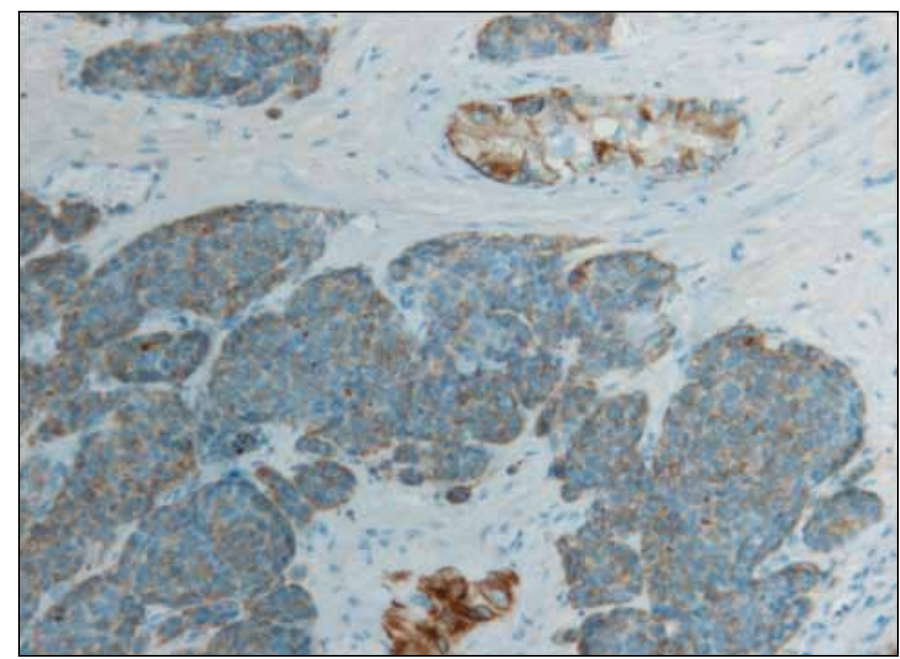

Fig. 2b. One of 4 neuroendocrine markers, keratine, positive and suggestive of a neuroendocrine (carcinoid) tumour.

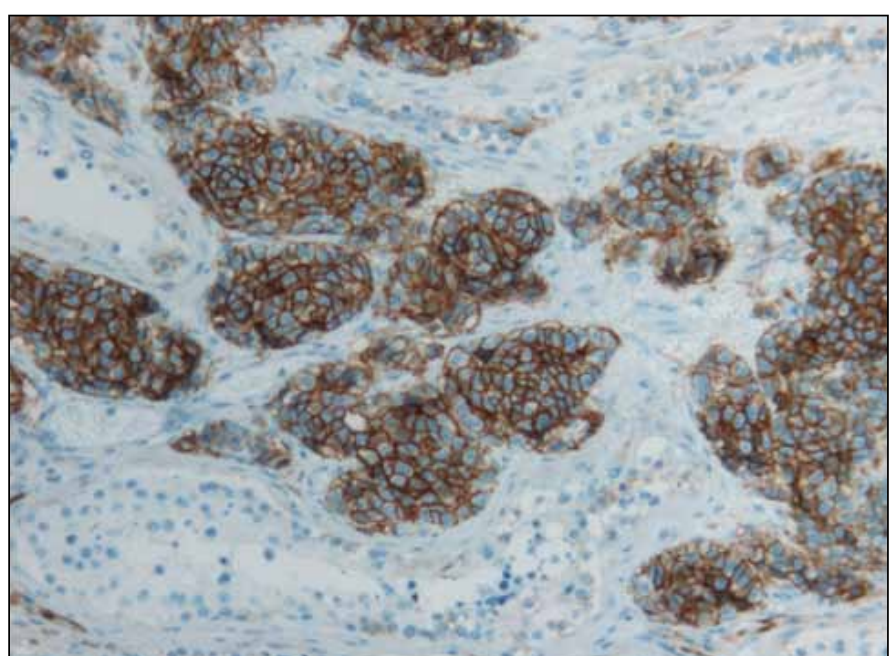

Fig. 2a. One of 4 neuroendocrine markers, CD56, positive and suggestive of a neuroendocrine (carcinoid) tumour.

lowed by the bronchopulmonary tract (25\%). In about $10 \%$ of cases, the primary tumour site remains unknown. ${ }^{4-6}$

The carcinoid syndrome occurs in $8 \%{ }^{5}$ of patients with a NET, however, it is encountered in over $80 \%$ of patients with liver metastases from bronchial carcinoids. ${ }^{7}$ Symptoms of the carcinoid syndrome include sweating, flushing, wheezing, diarrhea and abdominal pain. ${ }^{8}$

Cope was the first to describe a testicular metastasis from a carcinoid tumour of the ileum. ${ }^{9}$ Stroosma and colleagues found 62 published cases of carcinoid tumours of the testis between 1930 and 2008. Only six tumours were metastasis from another primary site, all of which originated from the ileum. ${ }^{8}$

Prognosis depends on tumour size and the presence of metastases. In distant metastatic disease the 5-year survival rate is only $(20 \%-30 \%) .{ }^{6}$ Somatostatin receptors are present

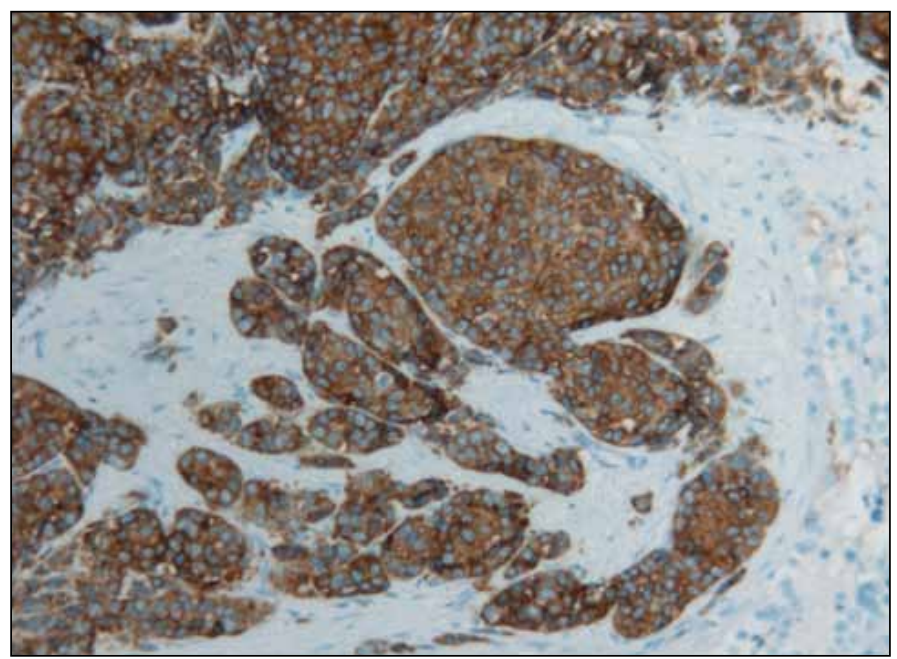

Fig. 2c. One of 4 neuroendocrine markers, synaptofysine, positive and suggestive of a neuroendocrine (carcinoid) tumour. 




Fig. 2d. One of 4 neuroendocrine markers, chromogranine, positive and suggestive of a neuroendocrine (carcinoid) tumour.

in $70 \%$ to $90 \%$ of NETs. A SRS (sensitivity $80 \%$ to $90 \%$ ) should be performed to exclude other tumour locations. ${ }^{10}$ The literature mainly focuses on the gastrointestinal tract as the primary site for a metastatic NET to the testes. ${ }^{2}$ In this case, the SRS was negative and the primary site could have been missed if a CT scan of the thorax and additional histological investigations, like a TTF-1, would not have been performed.

\section{Conclusion}

This case report describes a unique presentation of a metastasis from a neuroendocrine carcinoma of the lung, presenting itself as a palpable tumour of the testis. To our knowledge, this has never been reported in the literature. In spite of the presence of hepatic metastases, no carcinoid syndrome occurred. This case emphasizes the importance of not drawing any conclusions before additional investigations (pathology reports, PET/CT-scans and SRS) are known. It also

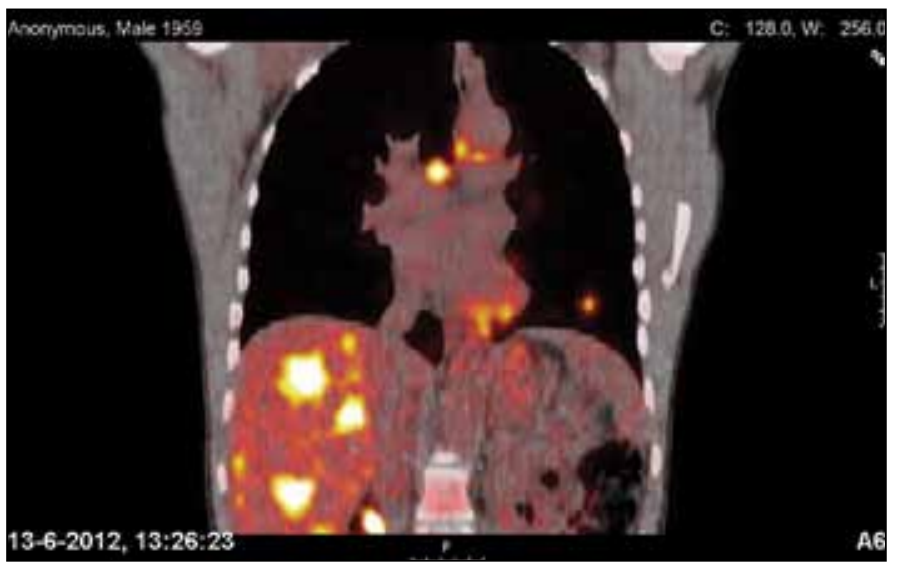

Fig. 4a. The positron emission tomography scan.

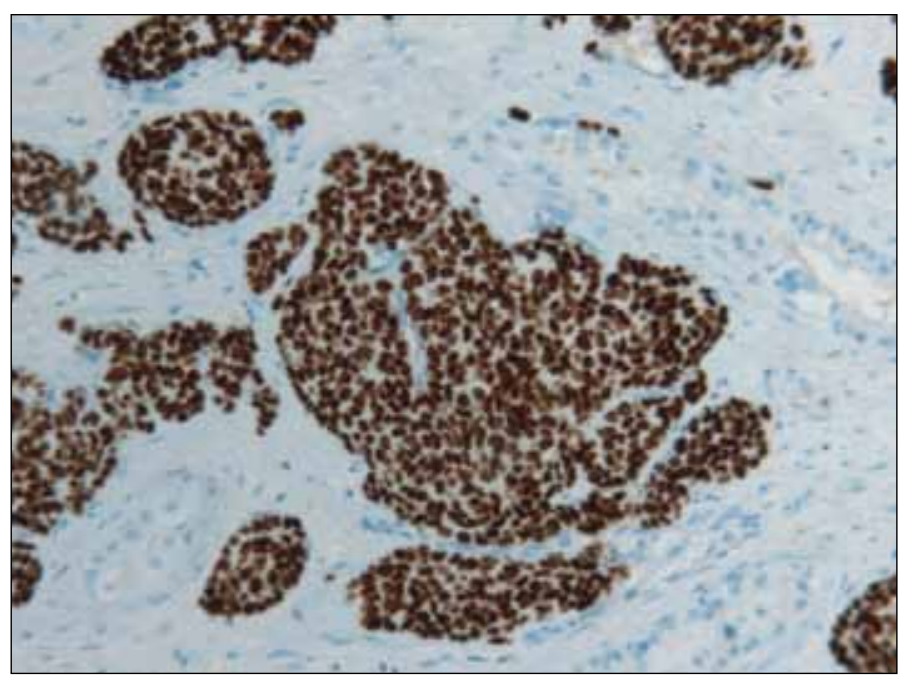

Fig. 3. The positive thyroid transcription factor 1 (TTF-1), suggesting a lung primary.

confirms the significance of a multidisciplinary meeting to tie up loose ends. The absence of a carcinoid syndrome cannot rule out extensive metastatic disease of a neuroendocrine carcinoma. This extraordinary diagnosis meant that no curative options were available in this young and vital patient.

Competing interests: None declared.

This paper has been peer-reviewed.

\section{References}

1. Reynard J, Brewster S, Biers S. Oxford Handbook of Urology. Second Edition. Oxford: Oxford University Press; 2009. http://dx.doi.org/10.1093/med/9780199534944.001.0001

2. Wang WP, Guo C, Berney DM, et al. Primary carcinoid tumours of the testis: a clinicopathologic study of 29 cases. Am I Surg Pathol 2010;34:519-24. http://dx.doi.org/10.1097/PAS.0b013e3181d31f33

3. Du EZ, Goldstraw P, Zacharias J, et al. TTF-1 expression is specific for lung primary in typical and atypical carcinoids: TTF-1-positive carcinoids are predominantly in peripheral location. Hum Pathol 2004;35:825-31. http://dx.doi.org/10.1016/i.humpath.2004.02.016

4. Modlin IM, Latich I, Kidd M, et al. Therapeutic options for gastrointestinal carcinoids. Clin Gastroenterol Hepatol 2006;4:526-47. http://dx.doi.org/10.1016/i.cgh.2005.12.008

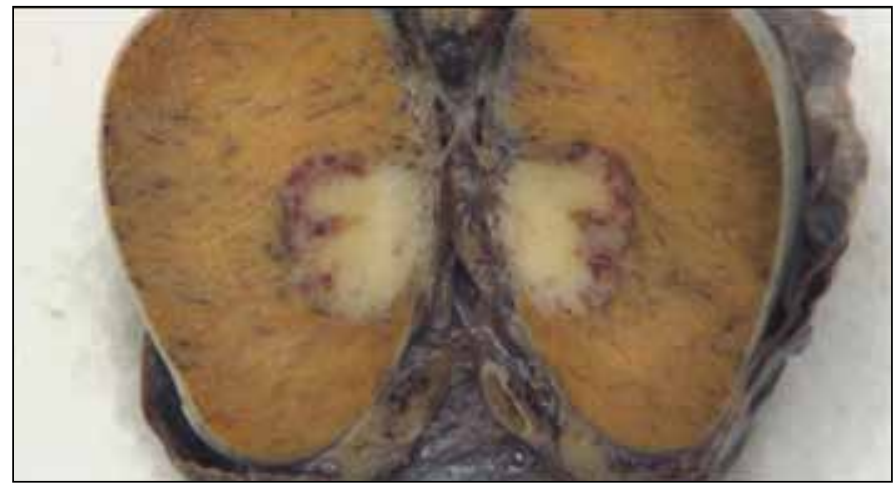

Fig. 4b. A macroscopic look at the tumour. 
5. Soga J, Yakuwa Y, Osaka M. Carcinoid syndrome: a statistical evaluation of 748 reported cases. J Exp Clin Cancer Res 1999;18:133-41.

6. Zuetenhorst JM, Taal BG. Metastatic carcinoid tumours: a clinical review. Oncologist 2005;10:123-31. http://dx.doi.org/10.1634/theoncologist.10-2-123

7. Fischer $S$, Kruger $M, M c R a e ~ K$, et al. Giant bronchial carcinoid tumours: a multidisciplinary approach. Ann Thorac Surg 2001;71:386-93. http://dx.doi.org/10.1016/S0003-4975(00)02251-7

8. Stroosma OB, Delaere KP. Carcinoid tumours of the testis. BJU Int 2008;101:1 101-5. http://dx.doi. org/10.1111/i.1464-410X.2007.07360.x

9. Cope Z. Metastasis of an argentaffin carcinoma in the testicle. Br J Urol 1930;2:268-72. http://dx.doi. org/10.1111/i.1464-410X.1930.tb00005.x
10. Taal BG, Hoefnagel $C A$, Valdes Olmos RA, et al. Combined diagnostic imaging with 1311-metaiodobenzylguanidine and 111 In-pentetreotide in carcinoid tumours. Eur J Cancer 1996;32A:1924-32. http://dx.doi.org/10.1016/0959-8049(96)00241-9

Correspondence: Dr. Ingrid L. Birker, St. Lucas Andreas Hospital, Jan Tooropstraat 164, 1061 AE Amsterdam; ibirker@gmail.com 